\title{
Adenocarcinoma de próstata metastático a pene
}

\author{
Cortés González JR, Garza R, Martínez R, Gómez L. \\ Servicio de Urología. Servicio de Anatomía Patológica. Hospital Universitario “José E. González” UANL. \\ Monterrey, NL. México
}

Actas Urol Esp. 2006;30(8):832-834

\section{RESUMEN}

\section{ADENOCARCINOMA DE PRÓSTATA METASTÁTICO A PENE}

El cáncer de próstata es una enfermedad que se presenta frecuentemente. A pesar de eso, la presencia de metástasis al pene son muy raras. Sólo se han descrito en la literatura 98 casos hasta el 2003. Presentamos el caso de un paciente con nódulos metastáticos en pene indoloros secundarios a cáncer de próstata.

Palabras clave: Cáncer prostático. Metástasis peneanas. Antígeno prostático específico.

\section{ABSTRACT \\ PROSTATE ADENOCARCINOMA METASTATIC TO PENIS}

Prostate cancer is a disease that appears with a very high frequency. However, the presence of metastasis to the penis is rare. Only 98 cases reported in the literature up to 2003. We present one case of a patient with painless metastatic nodules on the penis secondary to a prostate cancer.

Keywords: Prostate cancer. Penile metastasis. Prostatic specific antigen.

$\mathrm{L}^{2}$ a presencia de metástasis en el pene es infrecuente, aunque ha sido tratado numerosas veces en la bibliografía, incluyendo la bibliografia española $^{1,2}$. Existen sólo 98 casos descritos en la literatura hasta el $2003^{3}$. La afectación del pene indica generalmente mal pronóstico con una sobrevida de 6-12 meses independientemente del tratamiento utilizado ${ }^{2-4}$.

\section{PRESENTACIÓN DEL CASO Y SU MANEJO}

Varón de 88 años de edad con historia de síntomas urinarios bajos de menos de 2 años de duración, dolor en región lumbar y un episodio de retención urinaria aguda, tratado con colocación de sonda transuretral. Acude a nuestra institución para solicitar atención médica. Al examen físico, próstata fija de consistencia pétrea altamente sugestiva de malignidad. En esa ocasión el paciente no presentaba ninguna lesión en pene. El antígeno prostático específico (APE) era de $100 \mathrm{ng} / \mathrm{ml}$. Se realizó biopsia trans-rectal guiada por ultrasonido sin complicaciones. El estudio histopatológico reveló un adenocarcinoma de próstata indiferenciado Gleason 9 (4+5). Tras este episodio de retención urinaria se le ofreció resección transuretral de la próstata (RTU-P) y castración quirúrgica pero el paciente no la aceptó. Dos meses después, el paciente continuó con sonda transuretral y regresa a nuestra institución tras notar la presencia de nódulos ulcerados en la cara ventral del pene (Fig. 1A). Se le realizó RTU-P además de la castración quirúrgica y biopsia incisional de las lesiones en pene. El estudio histopatológico del tejido obtenido de la RTU-P y de la biopsia peneana confirmó el diagnóstico de adenocarcinoma de próstata Gleason $9(4+5)$ metastático a pene. (Fig. 2). Once meses después de la castración quirúrgica el APE estaba en 3,34 ng/ml. Las metástasis persisten sin causar dolor alguno y disminuyeron de tamaño en un 40\%. (Fig. 1B). 

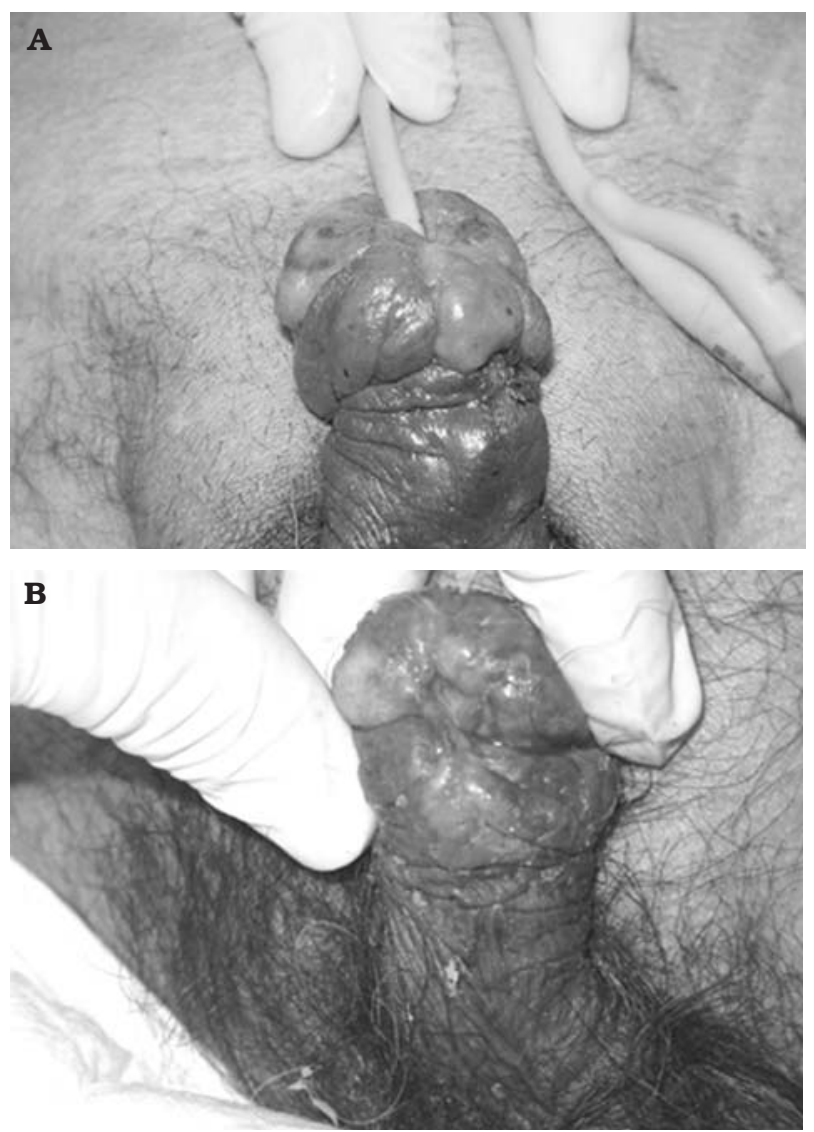

FIGURA 1. Lesiones metastásicas de tipo nodular en la cara ventral del pene antes (Imagen $A$ ) $y$ once meses después de la castración quirúrgica (Imagen B).

\section{DISCUSIÓN}

La afectación metastásica del pene es muy rara, los tumores que la afectan con mayor frecuencia son la próstata, la vejiga, el sigmoides y el riñón ${ }^{4,6}$. En el caso de los tumores de próstata, la diseminación ocurre por vía linfática, hematógena o por extensión directa ${ }^{3,5}$. En este caso la retención urinaria pudo haber causado una elevación en la presión intraprostática y esto pudo facilitar la propagación retrograda de las células prostáticas cancerígenas en los senos venosos del pene ${ }^{5}$.

El tratamiento de las metástasis en pene continúa siendo una controversia, algunos autores promueven la falectomía parcial, total o la deprivación androgénica ${ }^{3,4}$. Entre las indicaciones de la falectomía, está la presencia de dolor intenso de difícil manejo. En nuestro caso, la decisión de no realizar una falectomía se basó en la ausencia de dolor asociado a las metástasis.
Revisando la literatura, sólo 98 casos se habían revisado hasta el 2003. El promedio de edad fue de 70 años (42-93) y las formas de presentación incluyeron síntomas urinarios bajos $(28,5 \%)$ priapismo $(50 \%)$, dolor en pene $(16,3 \%)$ y la presencia de nódulos palpables $(7,1 \%)^{3}$. En nuestro caso, la presencia de nódulos indoloros lo hace más raro aún, ya que sólo se han descrito 7 casos de esta variante ${ }^{3}$.

El sitio más común de la localización de las metástasis fueron los cuerpos cavernosos, seguido por el glande, uretra y prepucio respectivamente $^{3}$. El pronóstico de los pacientes con metástasis en pene es malo con una sobrevida de 6 meses $^{2,3}$.

Once meses posterior a la castración, el paciente se encuentra en buenas condiciones
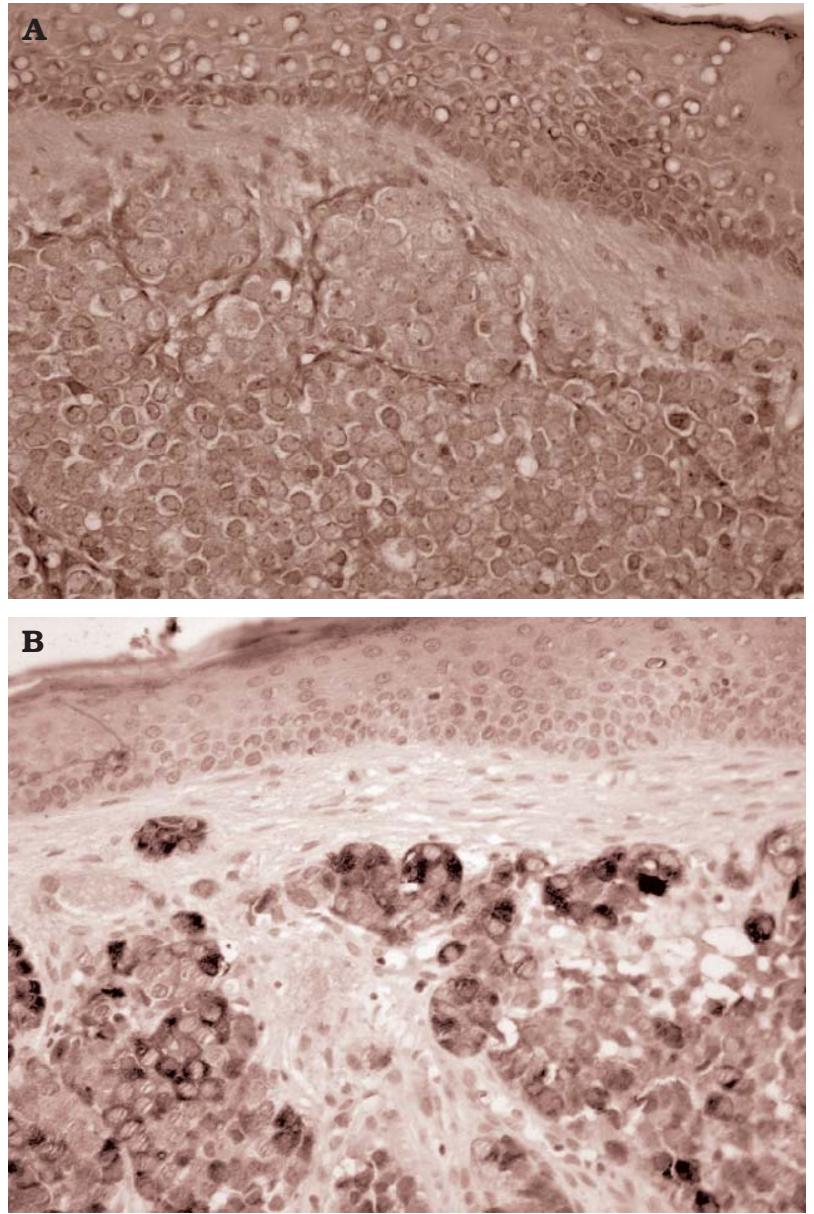

FIGURA 2. Piel de pene (teñido con Hematoxilina y Eosina 40x) Nidos de células neoplásicas poligonales con abundante citoplasma (Imagen A). Tinción positiva para APE (Imagen B). 


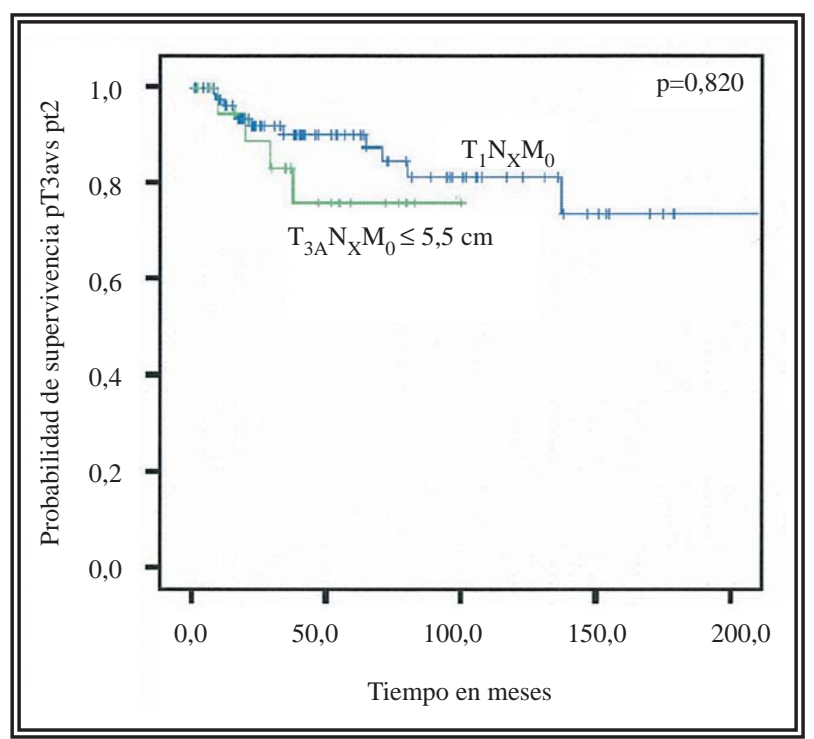

FIGURA 3.

generales, presenta micción espontánea satisfactoria, con una reducción apreciable de las lesiones metastásicas lo cual contrasta con lo descrito en la literatura mundial (Fig. 3).

\section{Agradecimientos}

Especial para el Prof. Dr. Med. Urs E. Studer por su colaboración en este trabajo.

\section{REFERENCIAS}

1. Alonso Gorrea M, Guillen Navarro M, Tramoyeres Celma A, Rodriguez Hernandez JH, Ferrutxe Frau J, Puig Giro R. Metastatic tumors of the penis. Arch Esp Urol. 1980;33(2): 131-142.

2. Rodrigues Netto $\mathrm{N}$ Jr, de Almeida Claro JF, Balthazar Saldanha L. Transitional cell carcinoma of the prostate metastatic to penis as cause of priapism. Arch Esp Urol. 1990;43(3):321-322.

3. Philip J, Mathew J. Penile metastasis of prostatic adenocarcinoma: Report of two cases and review of literature. World Journal of Surgical Oncology. 2003;55(4)1-16.

4. Mukamel E, Farrer J, Smith RB and De Kernion JB. Metastatic carcinoma to penis: when is total penectomy indicated? Urology. 1987;29(1):15-18.

5. Tu SM, Reyes A, Maa A, Bhowmick D, Pisters L, Pettaway $\mathrm{CA}$, et al. Prostate carcinoma with testicular or penile metastases clinical, pathologic, and immunohistochemical features. Cancer. 2002 May;94(10):2610-2617.

6. Hidayath Ansari, Ravi Prashant, Alison Franks. Prostatic carcinoma metastasis to the penis an uncommon site. Lancet Oncol. 2003 Nov;4(11):705-706.

Dr. J.R. Cortés González

E-mail: jrcor77@yahoo.com

(Trabajo recibido el 17 de marzo 2006) 